Review

\title{
Bioactive Functional Foods for Cardiovascular Diseases
}

\author{
${ }^{1}$ Kiren Mustafa, ${ }^{2}$ Iqra Ajmal, ${ }^{1}$ Tahira Naz, ${ }^{1}$ Abu Bakr Ahmad Fazili, ${ }^{1}$ Xueyuan Bai and ${ }^{1}$ Yuanda Song \\ ${ }^{1}$ Colin Ratledge Center of Microbial Lipids, Shandong University of Technology, \\ School of Agriculture Engineering and Food Science, Zibo 255049, China \\ ${ }^{2}$ Shanghai Key Laboratory of Regulatory Biology, School of Life Sciences, \\ East China Normal University, Shanghai, 200241, China
}

\author{
Article history \\ Received: 08-06-2020 \\ Revised: 18-07-2020 \\ Accepted: 04-08-2020 \\ Corresponding Author: \\ Xueyuan Bai \\ Colin Ratledge Center of \\ Microbial Lipids, Shandong \\ University of Technology, \\ School of Agriculture \\ Engineering and Food Science, \\ Zibo 255049, China \\ Email: baixy@sdut.edu.cn \\ Yuanda Song \\ Colin Ratledge Center of \\ Microbial Lipids, Shandong \\ University of Technology, \\ School of Agriculture \\ Engineering and Food Science, \\ Zibo 255049, China \\ Email: ysong@sdut.edu.cn
}

\begin{abstract}
Cardiovascular Disease (CVD) is a chronic pathological disorder regarded as a serious health concern round the globe. It is a multifactorial disease, with a range of various causative agents, among that dietary factor is considered the most important and may to a large degree determine CVD risk. Unfortunately, it has been less widely investigated. This review outlines the general aspects of CVD, epidemiology, risk factors and emphasizes the use of functional foods for the prevention and treatment of cardiovascular diseases. It highlights the importance of various foods used in daily routine and their activity against CVDs particularly. Recent studies have investigated the consumption of various foods including soybeans, oats, psyllium, flaxseed, garlic, tea, fish, grapes, nuts, fruits, vegetables, chocolate and sterol ester enhanced margarine etc., on CVD patients and their role as a natural/socioeconomic cure over chemical based drugs. Adequate intake of these foods on a constant basis, help in decreasing the risk of cardiovascular disease by several potential mechanisms e.g., lowering blood lipid levels, improving arterial compliance, reducing low-density lipoprotein oxidation, decreasing plaque formation, scavenging free radicals and inhibiting platelet aggregation etc. This review not only emphasizes the dire need of exploring safe functional foods against alarming rise of CVD cases, but also provides future insight in the use of bioactive food components in CVD therapeutics, as they are cost effective and have fewer side effects.
\end{abstract}

Keywords: Functional Foods, Bioactive Compounds, Cardiovascular Disease

\section{Introduction}

Cardiovascular diseases are one of vast group of diseases involving the heart and blood vessels. Cardiovascular diseases are still the leading cause of mortalities in the world (Sacco et al., 2016), in 1990 the mortality was 12.3 million $(25.8 \%)$ and in 2016 it reached up to 17.6 million deaths (Lozano et al., 2012; Abubakar et al., 2015; Naghavi et al., 2017). The categories of CVD include coronary artery diseases (plaques build up inside the coronary arteries) and angina leading to heart attack (blockage of arteries). Other types involve the stroke, hypertensive heart diseases, heart failure, cardiomyopathy, heart arrhythmia, venous thrombosis, rheumatic heart disease, congenital heart diseases and valvular heart diseases. Coronary artery disease and stroke are responsible for $80 \%$ of CVD deaths in males and $75 \%$ in females (Berrington de Gonzalez et al., 2010).
According to statistics by American Heart Association in 2016, one in every citizen in US was victims of CVD in 2013 (Mozaffarian et al., 2016). Initiation and progression of atherosclerosis (hardening of arteries) is the basis of many cardiovascular diseases, e.g., stroke, coronary artery disease and peripheral artery disease (Keenan et al., 2011; Herrera et al., 2020). The current theory of atherosclerosis formation postulates that endothelial injury by classical CVD risk factors (smoking, high blood pressure, elevated blood cholesterol) leads to trapping of LDL cholesterol within the arterial wall, which then oxidized and further activates the endothelium to secrete cytokines. This condition attracts circulating mononuclear cells expressing receptors for these cytokines and initiates a self-perpetuating inflammatory process. It causes the abnormalities in lipoprotein metabolism, chronic inflammation, oxidative stress and thrombosis (Singh et al., 2012). 
Table 1: Risk factors of cardiovascular diseases (Berry et al., 2012; Basharat, 2020)

\begin{tabular}{|c|c|c|c|}
\hline Non-modifiable metabolic & & Life style & Novel \\
\hline Advancing age & Obesity & Physical & Elevated homeostatic factors \\
\hline Male gender & Metabolic syndrome & Activity & Elevated inflammatory marker \\
\hline \multirow[t]{5}{*}{ Family history } & Diabetes & Smoking & Small dense LDL-C \\
\hline & Hyperlipidemia & Diet & Elevated lipoprotein level \\
\hline & - Hypertension & & Elevated homocysteine level \\
\hline & & & Oxidative stress \\
\hline & & & Endothelial dysfunction \\
\hline
\end{tabular}

Currently, the conventional cardiovascular risk factors (Table 1) have been broadly investigated, among them the dietary factors are considered very important and it may lead to determine high CVD risk factors such as blood pressure and dyslipidemia (Meier et al., 2019). As it is reported in 2011, High blood pressure resulted in $13 \%$ of CVD deaths, of which tobacco contributed $9 \%$, diabetes $6 \%$, lack of exercise $6 \%$ and obesity $5 \%$ of global deaths (Emerging Risk Factors Collaboration, 2011; Danaei et al., 2011).

Extensive epidemiologic studies suggest that diet habits and healthy life style could have a preventive effect on chronic illnesses like cardiovascular disease and on the other hand, poor habits exacerbate them. According to the report by World Health Organization (WHO), those populations consuming a large amount of fruits; vegetables as well as sea foods, were less prone to CVD cases (Meier et al., 2019). This finding brought a revolution in people's diet, they became more concerned about their daily diet intake that not only fulfill their nutritional demand but also down regulate the level of cholesterol, thus ultimately reducing the risk of cardiovascular diseases. As the name indicates, the term Functional food encompasses the food which is not only nutritionally important for our body but it is also involved in resolving diseased state of the body. It has various mechanism of actions, such as lowering elevated blood Total Cholesterol (TC) and Low-Density Lipoprotein (LDL) cholesterol, beyond the supply of basic nutrition (Boussageon et al., 2011). Thus, this review highlights the remarkable role of functional food, the active food components and their mechanism of action against CVD. The use of phytomedicine, plant and microbe-based food can play a feasible and socioeconomically beneficial role against chronic illnesses including CVD, compared to conventional therapy accompanied by poor health benefits. Thus, this review emphasizes the dire need for clinical trials investing in tremendous range of mentioned functional foods/nutraceuticals and directs researchers to explore more functional foods or bioactive food components against CVD and other chronic disorders as well.

\section{Functional Food as Prevention and Treatment}

In 2014, American Dietetic Association emphasizes that functional food must have a beneficial effect, even when consumed as a part of a diet at regular basis. It must be included as a whole, fortified, enriched or enhanced food forms (Lackland et al., 2014). Oxidative stress is one of the major causes of physiological disorders, such as cancer, diabetes and CVDs. Free radicals are continuously being produced during normal cellular metabolism as a consequence of leakage of electrons from electron transport chain to outside, that happens in different circumstances, such as part of cell signaling, homeostasis and cellular defense against invading pathogens (Kamiloglu et al., 2014; Dibanda et al., 2020). The antioxidant combat can be achieved either endogenously or exogenously by food. Thus, functional foods show significant benefits by releasing the Phytochemical, vitamins and minerals that is thought to be able of scavenging the free radicals produced during oxidative stress (Granato et al., 2020). Thus, they reduce the risk of CVD as well as it is beneficial for preventing and treating the CVD (Liu et al., 2012) and other disorders. This review summarizes, with an emphasis on clinical findings, recent literature supporting the efficacy for various functional foods in CVD risk reduction and treatment: Soybeans, oats, psyllium, flaxseed, garlic, ginger, tea, dark chocolate, fish, grapes, nuts, fruits, vegetables and stanol and sterol ester-enhanced margarine etc.

\section{Soy Proteins}

The obesity and CVD are the common physiological disorders in the world (Basharat, 2020). Food and Drug Administration (FDA) approved the soy protein as a functional food to reduce the risk of cardiovascular diseases a long ago. A meta-analysis based on 46 studies by FDA proved that soy protein confers heart protective role by decreasing significantly total cholesterol and LDL in the blood of adult population (Blanco Mejia et al., 2019). It was observed that the vegetarian Chinese and Japanese population consuming soy-protein in their diet, have a low cholesterol, LDL$\mathrm{C}$, low ischemic and cerebrovascular events (Food and Drug Administration, 1999). Soy-protein contains plant substances like isoflavones similar to estradiol, is responsible for lowering of cholesterol. In addition to isoflavones, soy-proteins contain saponins, phytic acids, trypsin inhibitors, fibers and globulins. These chemicals make the soy protein a beneficial functional food as it lower the blood lipids, improved arterial 
compliances, lipid metabolism and reduce the LDLoxidation (Gil-Izquierdo et al., 2012).

These findings direct the addition of soy-protein in daily diet, as it reduces the risk of the onset of diseases as well as it has a therapeutic potential. FDA set the daily dose of soy-protein as $25 \mathrm{~g}$ /day. Some data also suggest that even less than $25 \mathrm{~g}$ may effectively lower the blood lipids. 51 premenopausal women consumed the 20 $\mathrm{g}$ soy protein per day in 5 weeks resulted in $7 \%$ reduction in LDL and 6\% in total cholesterol (Hodis et al., 2011). In another study it is revealed that the significant level of isoflavones is involved in down regulation of cholesterol. 13 cardiac patients who consumed three different levels of isoflavones (10, 64.7 and $128.7 \mathrm{mg})$, only the highest intake of isoflavones significantly lowered LDL cholesterol by 7.6 to $10 \% \quad(P<0.05)$ (Wofford et al., 2012).

Food enriched in soybean has been reported conferring lipid lowering effect and thus reducing CVDs and obesity as well. Soya bean and soy based products have bioactive components such as, globulin proteins including glycinin and beta-conglycinin, oligosaccharides, phytosterols (campesterol, sitostanol and sitosterol) and anti-oxidant compounds. They have been reported to confer health promoting beneficial effects on both human and animal health. A supplemented product of soybean protein, glycine max has been found effective against CVDs by improving triglycerides and lipids profile and obesity (Basharat, 2020).

\section{Oat Soluble Fiber}

Oat soluble fiber is also known as viscous soluble fibers, contains $\beta$-glucan (Joyce et al., 2019). It reduces the LDL in the blood and confers protection against CVDs. It also contains phenolic compounds, xyloglucan, arabinoxylan, insoluble fiber, lipids, protein, vitamins and minerals. It reduces the blood lipid either by reducing the absorption of cholesterol and bile acids or by delaying the lipid digestion. Another mode of decreasing cholesterol in blood was found rise in thickness of gut contents (Wolever et al., 2010), which increases the excretion of cholesterol and bile salts from the gut. Now a day, large amount of research has indicated that not only the viscous properties of $\beta$-glucan confer cholesterol lowering impact but also there is a role of gut microbiota in maintaining the cholesterol homeostasis in the gut (Jonsson and Bäckhed, 2017; Joyce et al., 2019). The Oat meal or Oat $\beta$-glucan regulates the gut microbiota as well. The gut microbes metabolizes the bile acids (precursor of which is cholesterol) and hence increases the excretion of cholesterol from the body along with the faces, thus reducing the serum cholesterol level in experimental animals, humans and in-vitro fermentation systems (Wolever et al., 2010). A microbe centered review suggested that signaling of bile acids via farnesoid $\mathrm{X}$ receptors also influence the transport of cholesterol from gut into the blood, it increased the de novo synthesis of bile acids and increased the Trans intestinal cholesterol excretion (Joyce et al., 2019). Moreover the microbes in the gut also produce short chain fatty acids that also interfere with the metabolism of cholesterol (Ryan et al., 2015) via production of short chain fatty acids, degradation of cholesterol or microbial exopolysaccharides (Joyce et al., 2019). Overall these mechanisms altogether regulate the cholesterol homeostasis in the host and confer protection against heart diseases. Some studies on pigs fed with $\beta$-glucan also suggested that changes in cholesterol metabolism (lowering of serum cholesterol) were in agreement with the changes in gut microbiota (Begley et al., 2006). Fibers also have a function in preventing the constriction of arteries by reducing the LDL oxidation, thus work as a preventive and treatment agent for CVD disease (Othman et al., 2011).

Clinical study reveal that $3 \mathrm{~g}$ of $\beta$-glucan is required to reduce the $5 \%$ serum cholesterol which is approximately equals to $60 \mathrm{~g}$ of oat meal and $40 \mathrm{~g}$ of oat bran. FDA approved the use of $60 \mathrm{~g}$ oat meal per day either in one serving ( $60 \mathrm{~g}$ oat meal $=3 \mathrm{~g} \beta$-glucan $)$ or in different servings ( $20 \mathrm{~g}$ oat meal $=1 \mathrm{~g} \beta$-glucan $)$. It will reduce the total cholesterol and LDL by $2 \%$ and act as a treatment of CVD (Matthews et al., 2011).

\section{Psyllium Seed Husk}

Another viscous soluble fiber that has been shown to be very effective in lowering blood lipids is derived from the husk of the blonde psyllium seed, defined as the dried seed coat (epidermis) of the seed of Plantago ovata. Like soy-proteins, it also reduces the LDL cholesterol by lowering the oxidation (Ahmadi et al., 2012a). The FDA determined that the effective daily intake of soluble fiber from psyllium associated with a significant reduction in serum lipids was $7 \mathrm{~g} /$ day (equivalent to $10.2 \mathrm{~g}$ of husk) and would be expected to reduce total cholesterol 4 to $6 \%$ and LDL cholesterol, 4 to $8 \%$ (Smith and Tucker, 2011). The efficacy of psyllium in the treatment of hypercholesterolemia, even in the treatment of individuals with mild-to-moderate hypercholesterolemia who have type 2 diabetes, appears clear. In another study, 163 subjects treated with psyllium results in reduction of LDL cholesterol by $5-7 \%$ (Ahmadi et al., 2012b). Thus, it is the functional food that fills the gap between the diet and drug therapy.

\section{Flaxseed}

Flaxseed is a unique plant contains two significant components: (1) $\alpha$-linolenic acid, mega- 3 fatty acid; and (2) the lignans, a primary class of phytoestrogens. The $\alpha-$ linolenic acid content of flaxseed is the highest of any seed oil (57\%) and the lignan content of flaxseed is 800 
times higher than in 66 other plant foods, gives it a unique property. It shows a potential benefit for cardiovascular diseases, hypertensive, cancer and hormone replacement therapy (Khalesi et al., 2015). The antiesterogenic activity gives it a therapeutic effect used by the cancer patients as well as an alternative to hormone replacement therapy in women of Australia, United Kingdom and New Zealand (Rodriguez-Leyva et al., 2013). The research was conducted on 29 hyperlipidemic subjects (22 men and 7 postmenopausal women), consumed $20 \mathrm{~g}$ of fiber per day in 3 weeks, results into $4.6 \%$ TC and $7.6 \%$ LDL reduction with highly significant $\mathrm{P}$ value $=0.001$ (Caligiuri et al., 2014). Thus, it is also being used as a treatment of cardiovascular diseases as it reduces the blood pressure, LDL cholesterol and total cholesterol.

\section{Mushrooms}

Mushrooms are considered as an excellent source of antioxidants, extremely valuable for health promotion and disease prevention including heart diseases protection. Thus, many mushrooms species are available in market as functional food as well as nutraceuticals for medical health benefits (Reis et al., 2017). It has a large number of antioxidant compounds e.g., phenolic compounds, Vitamin $\mathrm{E}$ and vitamin $\mathrm{C}$ and carotenoids (Ferreira et al., 2009). Besides, mushrooms have unsaturated fatty acids, proteins and amino acids like leucine, valine and lectins, carbohydrates, mainly polysaccharides e.g., lentinan (Giavasis, 2014). Many studies reported direct association between mushroom extract and its bioactive compounds mainly phenolic compounds, thus such studies suggested the use of mushrooms in the form of various formulations as functional foods or its extract as a natural source of antioxidants in human food (Kimatu et al., 2017). Most of the studies on mushrooms are based on in-vitro assays, however some in vivo studies also reported the anti-oxidant potential of mushrooms, such as a study based on the ethanol extract of a mushroom (Agaricus bisporus), rich in gallic acid, catechin, ferulic acid, protocatechuic acid, caffeic acid and myricetin, involved feeding this extract to mice for 30 days on a daily basis (Liu et al., 2013). They found increase activity of antioxidant enzymes in the serum, liver and heart of mice. Similar findings were reported about Pleurotus species of mushrooms on the rats fed with the extract (200 mg/kg of body weight) for 4 days (Liu et al., 2013). Some of these studies recognized these anti-oxidant properties to were due to lectins, rutin, chrysin, $\beta$-carotene as well as $\alpha$-tocopherol, total phenolic compounds and ascorbic acid. In rats induced with oxidative stress by $\mathrm{CCl}_{4}$ treatment, mushrooms (specifically Pleurotus ostreatus) have been found to improve the activity of antioxidant enzymes and decreased MDA in blood serum and in vital organ (Jayakumar et al., 2008). It was found that insoluble/non-starch polysaccharides from these mushrooms played important anti-oxidant role. Apart from most studied anti-oxidant, immune-modulatory and anti-tumor properties, mushrooms also confer antiinflammatory, anti-diabetic and hypocholesterolemic effects which ultimately confer cardio-protective role (Valverde et al., 2015). All of these studies spotted light on the importance of mushrooms to use as functional foods and nutraceuticals. On the basis of these bioactive compounds, mushrooms have a great potential in food market, but there are some problems and concerns regarding their safety, standardization, efficacy and regulation and mode of action (Jayakumar et al., 2008; Wasser, 2014).

\section{Garlic}

Garlic (Allium sativum) is ranked as the top herbal product used by all over the world. Its beneficial or health promoting effects are vital to treat atherosclerosis and heart diseases. This is the best functional food as far as known yet. The intact garlic bulb contains odorless amino acid known as alliin, when the garlic is crushed the enzymes allinase releases and convert the alliin into allicin. Allicin is the compound which gives a characteristic odor to the garlic, then spontaneously, the allicin decomposes into many sulphur containing compounds (Beato et al., 2011). These compounds give it a medicinal property by lowering the cholesterol level and blood pressure in cardiovascular patients (Omar and Al-Wabel, 2010). The garlic has excellent ability to lower the cholesterol level in blood, maintaining lipid profile, reduce LDL oxidation, increase the fibrinolysis and decrease fibrinogen level in the blood (Sobenin et al., 2019).

A study conducted in 60 cardiac rehabilitation patients who received either two garlic capsules daily (each capsule contained ethyl acetate extract from $1 \mathrm{~g}$ peeled and crushed raw garlic) or placebo for 3 months showed a significant reduction in serum $\mathrm{TC}$ and triglycerides as well as an increase in HDL-cholesterol and fibrinolytic activity. FDA sets two capsules of garlic as a daily dose to reduce the risk as well as for treatment of the CVD (Ried et al., 2013). The lipid lowering effect of garlic has been most studied, the garlic oil, of which the bioactive component Diallyl disulfide, has been found to have effect as statins (Badr and Arafa, 2020). It was reported to inhibit the 3 Hydroxy 3 Methylglutaryl CoA (HMG CoA) reductase enzyme. It keeps the inactivated state of this enzyme by forming internal protein disulfide bridges that become unavailable for reductase (dithiothreitol) enzyme (Badr and Arafa, 2020). The aged garlic extract contained another active agent with antioxidant as well as hypolipidemic properties, S-allyl cysteine that reduced the blood 
cholesterol level, significantly reduced the level of triglycerides, ALT, AST and glutathione activity in the rats (Tran et al., 2018; Badr and Arafa, 2020). These effects were reported to be higher for the garlic extract rather than S-allyl cysteine alone, thus there must be some more bioactive ingredients with lipid lowering and antioxidant/anti-inflammatory properties in the garlic extract (Badr and Arafa, 2020; Raji et al., 2019).

Another study reported the effect of garlic oil and onion oil on blood lipid profile of hyperlipidemic rats (Yang et al., 2018). In this study, rats received volatile oil extract of garlic and onion for 60 days, they reduced the body weight, fats, total fats, total cholesterol and LDL-C and improved HDL-C, thus both of mentioned oils improved blood lipid profile and decreased body weight of rats effectively (Yang et al., 2018).

Apart from hypolipidemic effects, garlic also confers anti-hypertensive effects by inhibiting enzyme that converts angiotensin, reduces prostanoids that causes vasoconstriction (Asdaq and Inamdar, 2010).

The evidences suggest the use of garlic as a therapy against atherosclerosis and prevention (Sobenin et al., 2019).

\section{Ginger}

Ginger (Zingiber officinale Roscoe) has been cultivated for medicinal and cooking purposes for at least two millennia. It contains several hundred valuable compounds. It is demonstrated that ginger has a potential to reduce the heart related issues (Shoaib et al., 2016). It inhibits the production of NO, inflammatory cytokines, Cyclo-Oxygenases (COX) and Lipoxygenases (LOX) which oxidizes the arachidonic acid and causes the arterial inflammation (Mojani et al., 2014). Ginger has great antioxidant ability, scavenges the free radicals and protects the cell membrane lipids from oxidation (Bak et al., 2012). A study evaluated the effect of garlic and ginger oil alone and along with exercise on postmenopausal women (Basharat et al., 2019). It demonstrated a reduction in body weight, \% of body fat, body mass index, the cholesterol level, LDL and triglyceride significantly as a result of combination therapy of exercise and garlic as compared to either treatment alone. Moreover, the garlic demonstrated superior effects as compared to ginger alone. Several studies reported lipid lowering effect of ginger (Shoaib et al., 2016); a meta-analysis based study reported the favorable effect of ginger on Triglycerol level and LDL-C, while having no effect on TC and HDL-C. Moreover, the low dose of ginger was found to have greater lowering influence on total cholesterol and Triglycerols (Pourmasoumi et al., 2018).

The study demonstrated that $4 \mathrm{~g}$ of ginger given daily for 4 months to coronary artery disease patients reduces the serum total cholesterol, LDL, triglycerides and phospholipids, reduced atherosclerotic lesions and raised HDL as effectively as conventional hypolipidemic drugs. It acts on the liver, reduces the cholesterol biosynthesis and increases its excretion (Saptarini, 2013). Another study suggested that the minimum effective dose of ginger is $1 \mathrm{~g}$, with a linear increase in efficacy with the increase of dose. In principle, ginger exhibits safer therapeutic effect than conventional cardiovascular drugs since its side effects to date are negligible.

\section{Dark Chocolate}

Cocoa (Theobroma cacao) is enriched with flavonoid, responsible for preventing and treating the cardiovascular disease. Flavonoid improves the NOdependent vasorelaxation, arteries dilation as well as reduces the blood pressure and LDL level (Ried et al., 2017). Furthermore it was found that it reduced the serum cholesterol level, meanwhile it raised the HDLcholesterol by reducing the oxidation of LDL. Another study revealed that white chocolate doesn't contain the flavonoid and thus show no response in CVD prevention and treatment (Katz et al., 2011).

A study on consumption of dark chocolate and serum level of liver enzymes and the risk of cardiovascular diseases, found that $81 \%$ of people consuming chocolate looked younger, physically more active and with fewer chronic illnesses. Chocolate consumption was found inversely associated with risk factors of cardio metabolic disorders, e.g., liver enzymes and insulin resistance (Alkerwi et al., 2016). Dark chocolate has low degree of absorption into intestine and hence low bioavailability, thus, lycosomal formulation of dark chocolate and Astaxanthin improved the signs of oxidative stress and hypoxia in aging population as indicated by blood markers (Petyaev et al., 2018). There are growing evidences reporting numerous health benefits of dark chocolate, it includes not only protection against CVDs but also maintain homeostasis, cognitive and brain development. Dark chocolate and raw cocoa powder has been reported to be most beneficial for the health as compared to milk added chocolates which reduces the bioavailability of flavanols. Many biological health benefits of cocoa derived products are mainly because of alkaloids and flavanols, which are enriched in dark chocolate and cocoa powder. Many in-vitro and in-vivo studies revealed the anti-oxidant potential of cocoa based products on signaling pathways, NO production and endothelial cells function. Dark chocolate currently is at center of scientific research because it has not only flavanols and alkaloids, but also fatty acids, polyphenols, amino acids and microelements as well.

\section{Tea Flavonoid}

Tea is the second most widely used beverage after water. Tea production is in million tones, with black tea 
$(76 \%)$, green tea $(22 \%)$ and oolong tea $(2 \%)$ in total (Cao et al., 2019). Green tea is derived from fresh dry leaves by steaming and drying at high temperature in a process that avoids oxidation of the polyphenolic compound (Bogdanski et al., 2012). These compounds comprise up to $30 \%$ of the total dry weight of fresh tea leaves and include flavandiols, flavonoids, phenolic acids and flavonols (commonly known as catechins). The four major green tea catechins are Epigallocatechin3-Gallate (EGCG), Epigallocatechin (EGC), Epicatechin-3Gallate (ECG) and Catechin (EC) (Cao et al., 2019). During the manufacture of black tea, fully dried tea leaves are subjected to a full fermentation process, during which the polyphenolic compounds are extensively oxidized. Thus, catechins are reduced to only 3 to $10 \%$ of the remaining solids while bisflavanols, the aflavins, other oligomers and the arubigins are formed, the latter accounting for more than $20 \%$ of the remaining solids. Oolong tea is a partially fermented tea product (van der Hooft et al., 2012).

The emerging evidences explain its efficacy against cancer and the heart diseases as well (Yuan, 2013). Study found that consumption of 1 cup of tea per day or more reduced the risk of MI by $44 \%$ in 340 cases compared with age, sex and community-matched nontea-drinking controls. Moreover, tea consumption also reduces the aortic atherosclerosis. The reported odds ratio for developing severe aortic atherosclerosis decreased from 0.54 to 0.31 , with the daily consumption of 1 to 2 cups of tea to the consumption of 4 or more cups per day, respectively (Hartley et al., 2013).

Some epidemiological studies revealed the protective effect of tea bioactive compounds in reducing CVD risk. A study demonstrated that flavonoids from tea showed strong anti-oxidant effect in reducing risk of CVD in dose dependent fashion, with $100 \mathrm{mg} /$ day intake of tea flavonoids decreased the mortality rate due to CVD by 4\% (Grosso et al., 2017). Moreover, It has been found that intake of tea flavanoids was inversely associated with CVD mortality the data from Department of Agriculture, United states demonstrated 0.34 HRs (Ivey et al., 2015). Apart from it, Polish community was found with high intake rate of polyphenols mainly derived from tea and coffee (Grosso et al., 2014). Further studies exhibited high tea intake and reduced CVD cases among same polish community. A cohort study on 700 Dutch men with the age of 65 to 84 years, intake of epicatechin among CVD patients was associated with reduced death rate due to heart diseases (Dower et al., 2016). Similarly a case control study conducted on Japanese men of middle age indicated that high blood serum level of EGCG was associated with decrease stroke rate among non-smoking individuals, with the OR of 0.53 at CI of $95 \%$ (Ikeda et al., 2018).
Oxidative stress has been found directly associated with the chronic ailments, including CVDs. Green tea is rich in polyphenols, glutamine, theanine and caffeine which were found to reduce the post stroke depression among mice and reduced oxidative stress and effectively modulated the defense (Di Lorenzo et al., 2016). Moreover EGCG were found to reduce oxidative stress in mice via MAPK and ERK pathway (Yang et al., 2015). Furthermore EGCG was found to reduce oxidative stress in myocardial muscles and free fatty acids in blood thus stopped the heart failure rate in mice induced with heart failure (Oyama et al., 2017). Theanine was also proved to protect $\mathrm{H} 9 \mathrm{c} 2$ cells from oxidative damage by increasing the antioxidant capacity such as increasing SOD and glutathione peroxidase, decrease in ROS level and NO level (Li et al., 2018).

All kinds of tea, like black tea, green tea and white tea along with their bioactive components as catechins, theanine, EGCG possess outstanding protective effects against CVD cases. The mechanism of actions involve decrease in blood lipid level, improvement of ischemia/reperfusion injury and endothelial cell's functions, decreasing oxidative damage and associated inflammation, as well as the safety of cardiomyocytes.

\section{Nuts}

Different types of nuts are studied as a functional food such as walnut, almonds, hazelnut, pecans and olive oil. Nuts are complex foods containing cholesterol lowering mono and polyunsaturated fatty acids, arginine (a precursor to the vasodilator nitric oxide), soluble fiber and several antioxidant polyphenols. The first study that involved mixed nuts (almonds, hazelnuts, or pecans) involved 12 hyperlipidemic women in a crossover design that lasted for two 4 week periods. Two tablespoons of almonds, hazelnuts, or pecans per day was consumed by the subjects, thus $13 \%$ total cholesterol, $16 \%$ LDL reduction was observed. Only walnut diet lowered the triglycerides by $8 \%$ and very low-density lipoprotein by $12 \%$ (Orem et al., 2013). A clinical trial was done for 3 months on 772 participants, diet enriched with virgin olive oil, walnuts and almonds were given to them. These nuts differ in fatty acid and micronutrient composition. Walnuts have a high content in Polyunsaturated Fatty Acids (PUFAs), particularly linoleic acid and $\alpha$-linolenic acid, n-3 fatty acid, while almonds are rich in MUFA. Whereas both nut types contain sizable amounts of phenolic compounds, walnuts are particularly rich in $\gamma$-tocopherol, while almonds contain abundant $\alpha$-tocopherol and are richer in phytosterols (Choudhury et al., 2014). The results of this experiments is clearly explained in the Fig. 1. 


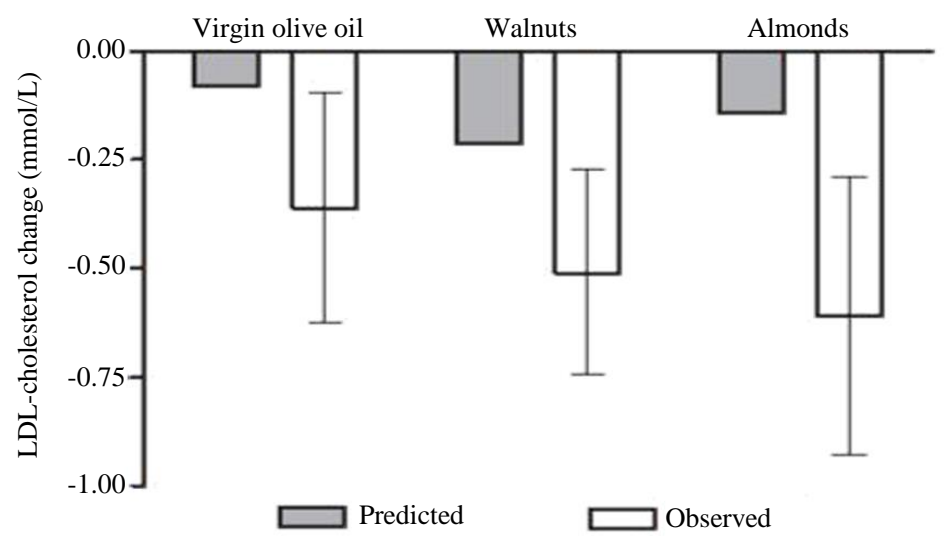

Fig. 1: Comparison of LDL cholesterol reduction by olive oil, almond and walnut (Damasceno et al., 2011)

A review based on interventional and observational studies from past 25 years indicated that nut intake conferred protection against CVDs, fatal as well as nonfatal heart diseases, sudden death because of heart attacks (Bitok and Sabaté, 2018). While a relatively weak protective effect was found against strokes. The nuts intake conferred protection against CVD basically by improving lipid profile as well as apolipoprotein profile in the blood. Further evidences reported other mechanisms of protection, such as decreasing inflammation and oxidative stress and refining the function of endothelial cells. Various bioactive compounds found in nuts impart crucial CVD protective role which are phytosterols, unsaturated fatty acids, phenolic compounds and Larginine. Another cohort study conducted in Spain, on 7447 individuals with high CVD risk, were fed with olive oil supplemented Mediterranean diet, nuts supplemented Mediterranean diet and control group fed with reduced fat intake (Estruch et al., 2018). After 4.8 years of study, it was observed that Mediterranean diet supplemented with either nuts or extra virgin olive oil, confers maximum protection against major cardiovascular (stroke, myocardial infarction, or death from cardiovascular causes) events (Estruch et al., 2018).

A larger than predicted hypocholesterolemic effect of nut-enriched diets indicated that the constituents responsible for this must be other than fatty acids, such as fiber, plant protein, tocopherols, phytosterols and possibly other bioactive components. Almond rich diet reduces the LDL cholesterol more than other two nuts. This diet is recommended as a treatment for the CVD patients (Berryman et al., 2011).

\section{Grapes, Grape Juice and Red Wine}

The grape juice in raw form may confer a lot of healthy effects, including the cardio-protective effect and curing CVDs. The bioactive compounds in grape juice influence on blood pressure, oxidative stress and inflammation, formation of fatty streaks, endothelial functioning and blood glucose level. Studies exhibited the effect of bioactive compounds in grape juice on LDL cholesterol, atherosclerosis and blood lipid profile as well (Ahmadi et al., 2019).

Over the last 20 years, numerous studies have been launched in an effort to explain the observation that the French population has a lower incidence of CVD than other Western populations despite the fact that they consume more fat (Ahmadi et al., 2019). In 1979 it was known as French paradox, the link between the wine intake and cardiovascular diseases is opposite. The mechanism behind the preventive effect of more grapes against the CVD is associated with its phenolic antioxidants (Li and Förstermann, 2012). Grapes contain a variety of antioxidants, including catechin, epicatechin, resveratrol and proanthocyanidins. Proanthocyanidins are present primarily in the seeds, whereas resveratrol $(3,4$ ', 5 trihydroxystilbene), a naturally occurring phytoalexin, is present mainly in grape skin at concentrations ranging from 50 to $100 \mathrm{mg} / \mathrm{g}$ (Hügel et al., 2016). Resveratrol may contribute to the heart health, other beneficial effects of grapes include, inhibition of lipid peroxidation, free radical scavenging activity, inhibition of platelet aggregation and vasorelaxation (Xia et al., 2010; Manna and Maiti, 2016) in humans.

In one study of 15 adults with angiography documented CVD, participants ingested $7.7 \mathrm{~mL} / \mathrm{kg} / \mathrm{d}$ of purple grape juice for 14 days. Short-term ingestion of purple grape juice reduced LDL oxidation and improved flow mediated vasodilation, which increased from 2.2 to $6.4 \%(P=0.003)$. The flavonoids in grapes are involved in reduction of platelet aggregation. In a randomized crossover study design, each of 10 healthy human subjects drank 5 to $7.5 \mathrm{~mL} / \mathrm{kg} / \mathrm{d}$ of purple grape juice, orange juice, or grape fruit juice, for 7 to 10 days. Drinking purple grape juice for 1 week reduced the whole blood platelet aggregation response to $1 \mathrm{mg} / \mathrm{L}$ of collagen by $77 \%$. Consuming red, purple and black grapes and grape juice on a constant basis may prove to be a practical recommendation as an adjunct therapy for preventing and managing heart diseases (Chamorro et al., 2012). 
Table 2: Comparison of phenolic compounds between grape juice and red wine (Barbalho et al., 2020)

\begin{tabular}{|c|c|c|c|}
\hline \multicolumn{2}{|l|}{ Red wine } & \multicolumn{2}{|l|}{ Grape juice } \\
\hline Flavanoids & Non-flavanoids & Flavanoids & Non-flavanoids \\
\hline Quercetin & Resveratrol & Flavanols & Phenolic acids \\
\hline Catechin & Benzoic acid & Flavonols & Resveratrol \\
\hline Epicatechin & Cinnamic acid & Anthocyanins & \\
\hline Anthocyanidin & Tannins & & \\
\hline
\end{tabular}

Procyanidins

The grapes species used for wine/juice production are, American variety (Vitis labrusca) and European variety (Vitis vinifera). The polyphenols found in red wine are gallic acid, caffeic acid, stilbenes also called trans-resveratrol, $\mathrm{p}$-coumaric acid and many flavonoids e.g., quercetin, myricetin, rutin, epicatechin and catechin (Ditano-Vázquez et al., 2019). Another study compared the grape juice and red wine in terms of health promoting benefits (Barbalho et al., 2020). They found that many antioxidant compounds can be lost during the processing of raw grapes to make wine or grapes juice. They found both the grape juice and red wine reduced the body mass index, peroxidation of serum lipids, glucose level, waist line, blood pressure, TC, LDL-C etc. (Barbalho et al., 2020). Both grape juice and red wine have many bioactive compounds conferring numerous health benefits for humans. Table 2 depicts the qualitative difference in phenolic compounds among red wine and grape juice.

\section{Fish Oil}

The inverse relationship between fish consumption and CVD was first brought to light nearly 30 years ago when it was reported that Greenland Eskimos had low rates of this disease despite consuming a diet containing approximately $7 \mathrm{~g} /$ day of omega-3 (n-3) fatty acids from marine fish (Saravanan et al., 2010). Fatty fish (salmon, tuna, mackerel, sardines and herring) and its oils are the predominant sources of the n-3 fatty acids Eicosapentaenoic Acid (EPA) and Docosahexaenoic Acid (DHA) (Behera, 2019). Supplements of EPA and DHA (1 g/d) are known to reduce the blood lipid (Peter et al., 2013). Potential mechanisms for the cardiovascular protective effects of n-3 fatty acids are suggested to be; anti-inflammatory, antithrombotic (reduced platelet aggregability) and antiarrhythmic (reducing the risk of potentially fatal cardiac arrhythmias), lowering of heart rate and blood pressure, hypotriglyceridemic and improved endothelial function (De Caterina, 2011). Fish oil increased platelet survival $(P<0.05)$ and lowered malondialdehyde formation. Platelet activation changes were related with significant reductions in total cholesterol (2.9\%), LDL cholesterol $(3.5 \%)$ and triglycerides $(12.4 \%)$. So, consumption of moderate amounts of fish (one to two servings per week) has been associated with reduced CVD related deaths, thus it acts as a therapy (Einvik et al., 2010).

A follow up study examined the diabetic patients of 18 years or high for cardiovascular disease associated mortalities and examined that the individuals consuming higher amount of fish were at low risk mortalities due to CVDs, especially strokes among diabetic patients (Deng et al., 2018). Another study suggested that consumption of mono-unsaturated fatty acids and medium chain triglycerides along with background diet can improve the effect of fish oil on CVD patients (Kondreddy et al., 2016); however it needs to be consulted prior to intake with the medical supervisor while taking heart disease therapy.

Another study in Egypt was conducted by using a mathematical model to find an association between fish consumption and mortalities due to chronic heart diseases. It was reported that when the consumption of fish from the total harvested fish increased with the avoidance of the behavioral and metabolic risk factors for coronary heart diseases, the associated mortalities decreased significantly in a specific duration of time (Ameen et al., 2020).

\section{Plant Sterol and Stanol Esters}

The cholesterol-lowering effect of plant sterols was first identified in the $1950 \mathrm{~s}$. Early research investigated the efficacy of large amounts of plant sterols (such as $\beta$ sitosterol, campesterol and stigmasterol), which are natural components of vegetable fats/oils and pine trees. Studies have found that plant stanols, the saturated derivatives of sterols (i.e., sitostanol), result in greater cholesterol-lowering than plant sterols because of their enhanced ability to reduce intestinal cholesterol absorption while remaining almost unabsorbed (Mensink et al., 2010). Structurally, plant sterols and stanols resemble cholesterol, which allows them to compete with cholesterol during its absorption in the digestive tract. Many researches have been conducted to find the mechanism of action of plant sterols (Scolaro et al., 2020), thus it was found that difference in hydrophobicity of plant sterols prevent the cholesterol from entering into the 
micelles and it precipitate along with cholesterol in the intestinal lumen, hence reduces the absorption of cholesterol into the blood stream. Moreover, it also interferes with the cholesterol transport in the blood along with affecting the metabolism of cholesterol (Bai, 2019). As such no significant side effects, including gastrointestinal effects, have been observed with the consumption of plant stanol or sterol esters, only conferred a minor effect on decreasing the serum carotenoid concentration (Smet et al., 2012). A clinical trial based study demonstrated that a plant stanol estercontaining margarine could significantly reduce both total and LDL cholesterol by 10 and 14\%, respectively, in mildly hypercholesterolemic patients. The consumption of foods containing at least 0.65 grams per serving of plant sterols, eaten twice a day with meals for a daily total intake of at least 1.3 grams, as part of a diet low in saturated fat and cholesterol, may reduce the risk of heart diseases (Ras et al., 2014).

\section{Fruit and Vegetables}

There is a large amount of literature that reported the beneficial effects of diets rich in vegetables and fruits on CVD risk. Conversely, inadequate consumption of fruit and vegetables has been linked with higher incidence of CVD (Key, 2011; Miller et al., 2019). The mechanisms by which fruit and vegetables exert their protective effects depend upon its constituents. Several bioactive components are carotenoids, vitamin C, fiber, magnesium and potassium these compounds give antioxidant property and ultimately reduce the LDL cholesterol (Zhang et al., 2011). Plant foods also contain bioactive compounds known as "phytochemicals." Some groups of phytochemicals which have or appear to have significant health potentials are carotenoids, phenolic compounds (flavonoids, phytoestrogens, phenolic acids), phytosterols and phytostanols, tocotrienols, organosulfur compounds and non-digestible carbohydrates (dietary fiber and prebiotics). The powerful antioxidant functions of vitamin $\mathrm{C}$ serve to reduce tissue reactive oxygen species concentrations, which in the atherosclerotic condition help prevent endothelial dysfunction, inhibit vascular smooth muscle proliferation and reduce oxidized LDL cholesterol (Song et al., 2010). In addition to its role as a free radical scavenger, vitamin $\mathrm{E}$ is also a potent antiinflammatory agent, at high doses. Mounting evidence supports the strong inverse association between plasma vitamin $\mathrm{E}$ and $\mathrm{CVD}$ as well as that between vitamin $\mathrm{E}$ intake and risk of CVD. Fruits and vegetables must be consumed more in order to reduce the CVD as well as during the treatment of CVD (Boffetta et al., 2010).
Currently, World Health Organization (2003) recommends a minimum intake of fruits along with vegetables to at least $400 \mathrm{~g} /$ day. Recently a metaanalysis based study reported that a fruit intake of 800 g/day was associated with $27 \%$ reduction in the risk for CVDs (Aune et al., 2017). Some epidemiological studies on postmenopausal women found an inverse relationship between grapefruit and strawberries intake and coronary heart diseases (Mink et al., 2007). Consumption of berries rich in anthocyanin and procyanidins was found to reduce the CVD risk factors including endothelial dysfunction, aggregation of platelets and atherosclerosis (Basu et al., 2010). Citrus fruits were found to improve the blood lipid profile by decreasing high cholesterol level. Similarly, fruit juices and fruit powder are effective way to deliver antioxidants rich compounds with less fibers. Fruit juice contains vitamins, polyphenols and minerals (Kamiloglu et al., 2014). Some other research based studies suggested that processing of fruits can increase the carotenoids especially lycopene content in the fruit juices (Kamiloglu et al., 2014). A review suggested that intake of fruit/vegetable juices confers similar benefits as do the whole fruit or vegetable (Kamiloglu et al., 2014).

Another systemic review explained the effect of consuming cherries, citrus fruit and berries on CVD risk factors, reported that cranberry or cherry juice can significantly decrease the blood pressure (Wang et al., 2020).

Apples are the most economical fruit crops with top nutrients and largely consumed in the world (Wang et al., 2018). Beneficial properties of apples are due to high content of total phenolic compounds and richness of fibers. Although environmental conditions, growing and storage conditions influence the diversity of apples, still the phenolic compounds found in apples mainly in their red peel are $4.6-25.48 \mathrm{~g} / \mathrm{kg}$ flavanols, $0.05-3 \mathrm{~g} / \mathrm{kg}$ of hydroxycinnamic acids, anthocyanins and $0.049-0.434 \mathrm{~g} / \mathrm{kg}$ of dihydrochalcones. Moreover, the apples are also rich source of vitamins (B1, B2, A, C, K) and other essential minerals (Iron, potassium, phosphorus and sugars) (Stirpe et al., 2017). A review based on eight observational studies and eight randomized trials, concluded that daily consumption of 100 to $150 \mathrm{~g}$ of whole apples is associated with reduction of blood pressure, pulse rate, inflammation, total cholesterol and LDL-C and increased HDL-C and improved the functions of endothelial cells. Thus, daily intake of apples helps in protecting against CVDs (Sandoval-Ramírez et al., 2020).

The mechanisms of functional foods used to prevent and treat the cardiovascular diseases along with their compounds are briefly explained in the Table 3 . 
Table 3: Functional food and their mechanism

\begin{tabular}{|c|c|c|}
\hline Potential mechanism & Bioactive compounds & Functional foods \\
\hline \multirow[t]{9}{*}{ Lowering blood cholesterol } & Tocopherol, omega-3 fatty acid & Nuts \\
\hline & Fibers, polyphenols & Legumes \\
\hline & Fiber & Fruits and vegetables \\
\hline & Phytosterols & Margarine \\
\hline & Omega-3 fatty acids & Fish oil \\
\hline & Fiber, Phytochemicals & Whole grains \\
\hline & Flavonoid & Dark chocolate \\
\hline & Omega-3 fatty acids & Fish \\
\hline & Carotenoids & Green leafy vegetables \\
\hline \multirow[t]{4}{*}{ Inhibition of LDL-C oxidation } & Vitamin C Polyphenolic, oleic acid & Citrus fruits vegetables Extra virgin olive oil \\
\hline & Tea polyphenolics & Green tea \\
\hline & Flavonoids & Dark chocolate \\
\hline & Polyphenol & Fruits, Pomegranate \\
\hline Lowering blood triglycerols & Omega-3 fatty acids & Fish \\
\hline \multirow{5}{*}{ Decreasing blood pressure } & Omega-3 fatty acids & Fish \\
\hline & Fiber, Phytochemicals & Whole grains \\
\hline & Ascorbic acid & Citrus fruits \\
\hline & Tea polyphenolics & Green and black tea \\
\hline & Grapes Polyphenol & Grapes and red wine \\
\hline \multirow[t]{4}{*}{ Lowering blood homocysteine } & Folates & Fruits and vegetables \\
\hline & Fiber, Phytochemicals & Whole grains \\
\hline & Vitamin C & Citrus fruits vegetables \\
\hline & Vitamin E & Nuts, seeds, oil \\
\hline \multirow[t]{5}{*}{ Antioxidant action } & Lycopene & Tomatoes \\
\hline & Carotenoids & Green leafy vegetables \\
\hline & Vitamin C & Citrus fruits vegetables \\
\hline & Tea polyphenolics & Green and black tea \\
\hline & Anthocyanins, catechins, flavonols & Grapes and red wine \\
\hline \multirow[t]{3}{*}{ Anti-inflammatory action } & Vitamin E & Nuts, seeds, oil \\
\hline & Omega-3 fatty acids & Fish \\
\hline & Anthocyanins, catechins, flavonols & Grapes and red wine \\
\hline \multirow[t]{5}{*}{ Endothelial function } & Omega-3 fatty acids & Fish \\
\hline & Polyphenols & Nuts \\
\hline & Vitamin C & Citrus fruits vegetables \\
\hline & Anthocyanins, catechins, flavonols & Grapes and red wine \\
\hline & Flavonoid & Dark chocolate \\
\hline Platelets aggregation & Anthocyanins, catechins, flavonols & Grapes and red wine \\
\hline
\end{tabular}

\section{Conclusion}

As CVD continues to be the leading cause of mortality all over the world, the alternatives and additional therapies are needed for prevention and treatment. Researchers found that the consistent consumption of some foods reduces the risk of CVDs. These foods such as psyllium seed husk, nuts, whole grain, tea, dark chocolate, garlic, ginger, grapes, wine, Oat fibers, fruits and vegetables provides beneficial effects to prevent and treat the cardiovascular diseases and thus known as functional foods. These are the best, cheap and less dangerous way of reducing the risk of CVDs. This food may potentially provide benefit alone, in combination and in addition to cholesterol lowering medications and with other therapies. Functional food is not only used to reduce the risk and for treatment of cardiovascular diseases but also used for many other diseases like cancer, blood pressure, asthma, hepatitis and other chronic diseases. The advances in the knowledge of both the disease and healthy dietary components have provided a new avenue to develop dietary strategies to prevent and to treat CVD. Although many of these functional foods have been found to have high therapeutic potential, future studies should include well-designed clinical trials assessing different combinations of these nutrients to realize possible additive and synergistic effects on health outcomes.

\section{Acknowledgement}

This work was supported by the National Natural Science Foundation of China (31670064, 31972851), the TaiShan Industrial Experts Program (tscy 20160101).

\section{Author's Contributions}

Kiren Mustafa: Proof reading, modification and review. 
Iqra Ajmal: Initial draft writing.

Tahira Naz: Table designing and critical analysis.

Abu Bakr Ahmad Fazili: Figure and interpretation.

Xueyuan Bai: Review and editing.

Yuanda Song: Conception and review.

\section{Competing Interests}

The authors announce that they have no competing interests.

\section{References}

Abubakar, I. I., Tillmann, T., \& Banerjee, A. (2015). Global, regional and national age-sex specific allcause and cause-specific mortality for 240 causes of death, 1990-2013: a systematic analysis for the Global Burden of Disease Study 2013. Lancet, 385(9963), 117-171.

Ahmadi, L., El-Kubbe, A., \& Roney, S. K. (2019). Potential Cardio-Protective Effects of Green Grape Juice: A Review. Current Nutrition \& Food Science, 15(3), 202-207.

Ahmadi, R., Kalbasi-Ashtari, A., \& Gharibzahedi, S. M. T. (2012a). Physical properties of psyllium seed. International Agrophysics, 26(1).

Ahmadi, R., Kalbasi-Ashtari, A., Oromiehie, A., Yarmand, M. S., \& Jahandideh, F. (2012b). Development and characterization of a novel biodegradable edible film obtained from psyllium seed (Plantago ovata Forsk). Journal of Food Engineering, 109(4), 745-751.

Alkerwi, A. A., Sauvageot, N., Crichton, G. E., Elias, M. F., \& Stranges, S. (2016). Daily chocolate consumption is inversely associated with insulin resistance and liver enzymes in the Observation of Cardiovascular Risk Factors in Luxembourg study. British Journal of Nutrition, 115(9), 1661-1668.

Ameen, I., Hidan, M., Mostefaoui, Z., \& Ali, H. M. (2020). Fractional optimal control with fish consumption to prevent the risk of coronary heart disease. Complexity, 2020.

Asdaq, S. M., \& Inamdar, M. N. (2010). Potential of garlic and its active constituent, S-allyl cysteine, as antihypertensive and cardioprotective in presence of captopril. Phytomedicine, 17(13), 1016-1026.

Aune, D., Giovannucci, E., Boffetta, P., Fadnes, L. T., Keum, N., Norat, T., ... \& Tonstad, S. (2017). Fruit and vegetable intake and the risk of cardiovascular disease, total cancer and all-cause mortality-a systematic review and dose-response meta-analysis of prospective studies. International journal of epidemiology, 46(3), 1029-1056.

Badr, G. M., \& Arafa, N. S. (2020). Synergetic effect of aged garlic extract and methotrexate on rheumatoid arthritis induced by collagen in male albino rats.
Bai, N. (2019, May). Advances in the Prevention of Cardiovascular Diseases by Phytosterol. In Proceedings of the third International Conference on Medical and Health Informatics 2019 (pp. 110-114).

Bak, M. J., Ok, S., Jun, M., \& Jeong, W. S. (2012). 6shogaol-rich extract from ginger up-regulates the antioxidant defense systems in cells and mice. Molecules, 17(7), 8037-8055.

Barbalho, S. M., Bueno Ottoboni, A. M. M., Fiorini, A. M. R., Guiguer, É. L., Nicolau, C. C. T., Goulart, R. D. A., \& Flato, U. A. P. (2020). Grape juice or wine: which is the best option?. Critical Reviews in Food Science and Nutrition, 1-14.

Basharat, A., Qamar, M. M., Basharat, N., Aslam, S., Rasul, A., \& Naqvi, F. (2019). Effect of Garlic, Ginger and Exercise on Lipid Profile in Healthy Postmenopausal Women. Annals of King Edward Medical University, 25(4).

Basharat, S. (2020). Therapeutic Effect of Glycine Max (Soybean) Bioactive Components in $\mathrm{Cvd}$ and Obesity. J Food Nutr, 6, 1-7.

Basu, A., Rhone, M., \& Lyons, T. J. (2010). Berries: emerging impact on cardiovascular health. Nutrition reviews, 68(3), 168-177.

Beato, V. M., Orgaz, F., Mansilla, F., \& Montaño, A. (2011). Changes in phenolic compounds in garlic (Allium sativum L.) owing to the cultivar and location of growth. Plant foods for human nutrition, 66(3), 218-223.

Begley, M., Hill, C., \& Gahan, C. G. (2006). Bile salt hydrolase activity in probiotics. Applied and environmental microbiology, 72(3), 1729-1738.

Behera, S. S. (2019). Dietary fish oil concentrates associated health benefits: A recent development of cardiovascular risk reduction. Current Pharmaceutical Design, 25(38), 4053-4062.

Berrington de Gonzalez, A., Hartge, P., Cerhan, J. R., Flint, A. J., Hannan, L., MacInnis, R. J., ... \& Beeson, W. L. (2010). Body-mass index and mortality among 1.46 million white adults. New England Journal of Medicine, 363(23), 2211-2219.

Berry, J. D., Dyer, A., Cai, X., Garside, D. B., Ning, H., Thomas, A., ... \& Lloyd-Jones, D. M. (2012). Lifetime risks of cardiovascular disease. New England Journal of Medicine, 366(4), 321-329.

Berryman, C. E., Preston, A. G., Karmally, W., Deckelbaum, R. J., \& Kris-Etherton, P. M. (2011). Effects of almond consumption on the reduction of LDL-cholesterol: a discussion of potential mechanisms and future research directions. Nutrition reviews, 69(4), 171-185.

Bitok, E., \& Sabaté, J. (2018). Nuts and cardiovascular disease. Progress in cardiovascular diseases, 61(1), 33-37. 
Blanco Mejia, S., Messina, M., Li, S. S., Viguiliouk, E., Chiavaroli, L., Khan, T. A., ... \& Jenkins, D. J. (2019). A meta-analysis of 46 studies identified by the FDA demonstrates that soy protein decreases circulating LDL and total cholesterol concentrations in adults. The Journal of nutrition, 149(6), 968-981.

Boffetta, P., Couto, E., Wichmann, J., Ferrari, P., Trichopoulos, D., Bueno-de-Mesquita, H. B., ... \& Nöthlings, U. (2010). Fruit and vegetable intake and overall cancer risk in the European Prospective Investigation into Cancer and Nutrition (EPIC). Journal of the National Cancer Institute, 102(8), 529-537.

Bogdanski, P., Suliburska, J., Szulinska, M., Stepien, M., Pupek-Musialik, D., \& Jablecka, A. (2012). Green tea extract reduces blood pressure, inflammatory biomarkers and oxidative stress and improves parameters associated with insulin resistance in obese, hypertensive patients. Nutrition research, 32(6), 421-427.

Boussageon, R., Bejan-Angoulvant, T., Saadatian-Elahi, M., Lafont, S., Bergeonneau, C., Kassaï, B., ... \& Cornu, C. (2011). Effect of intensive glucose lowering treatment on all cause mortality, cardiovascular death and microvascular events in type 2 diabetes: meta-analysis of randomised controlled trials. Bmj, 343.

Caligiuri, S. P., Aukema, H. M., Ravandi, A., Guzman, R., Dibrov, E., \& Pierce, G. N. (2014). Flaxseed consumption reduces blood pressure in patients with hypertension by altering circulating oxylipins via an $\alpha$-linolenic acid-induced inhibition of soluble epoxide hydrolase. Hypertension, 64(1), 53-59.

Cao, S. Y., Zhao, C. N., Gan, R. Y., Xu, X. Y., Wei, X. L., Corke, H., .. \& Li, H. B. (2019). Effects and mechanisms of tea and its bioactive compounds for the prevention and treatment of cardiovascular diseases: An updated review. Antioxidants, 8(6), 166.

Chamorro, S., Goñi, I., Viveros, A., Hervert-Hernández, D., \& Brenes, A. (2012). Changes in polyphenolic content and antioxidant activity after thermal treatments of grape seed extract and grape pomace. European Food Research and Technology, 234(1), 147-155.

Choudhury, K., Clark, J., \& Griffiths, H. R. (2014). An almond-enriched diet increases plasma $\alpha$-tocopherol and improves vascular function but does not affect oxidative stress markers or lipid levels. Free radical research, 48(5), 599-606.

Damasceno, N. R. T., Pérez-Heras, A., Serra, M., Cofán, M., Sala-Vila, A., Salas-Salvadó, J., \& Ros, E. (2011). Crossover study of diets enriched with virgin olive oil, walnuts or almonds. Effects on lipids and other cardiovascular risk markers. Nutrition, Metabolism and Cardiovascular Diseases, 21, S14-S20.
Danaei, G., Finucane, M. M., Lu, Y., Singh, G. M., Cowan, M. J., Paciorek, C. J., ... \& Rao, M. (2011). National, regional and global trends in fasting plasma glucose and diabetes prevalence since 1980: systematic analysis of health examination surveys and epidemiological studies with 370 country-years and $2 \cdot 7$ million participants. The lancet, 378(9785), 31-40.

De Caterina, R. (2011). n-3 fatty acids in cardiovascular disease. New England Journal of Medicine, 364(25), 2439-2450.

Deng, A., Pattanaik, S., Bhattacharya, A., Yin, J., Ross, L., Liu, C., \& Zhang, J. (2018). Fish consumption is associated with a decreased risk of death among adults with diabetes: 18-year follow-up of a national cohort. Nutrition, Metabolism and Cardiovascular Diseases, 28(10), 1012-1020.

Di Lorenzo, A., Nabavi, S. F., Sureda, A., Moghaddam, A. H., Khanjani, S., Arcidiaco, P., ... \& Daglia, M. (2016). Antidepressive-like effects and antioxidant activity of green tea and GABA green tea in a mouse model of post-stroke depression. Molecular nutrition \& food research, 60(3), 566-579.

Dibanda, R. F., Akdowa, E. P., \& Tongwa, Q. M. (2020). Effect of microwave blanching on antioxidant activity, phenolic compounds and browning behaviour of some fruit peelings. Food chemistry, 302, 125308.

Ditano-Vázquez, P., Torres-Peña, J. D., Galeano-Valle, F., Pérez-Caballero, A. I., Demelo-Rodríguez, P., Lopez-Miranda, J., ... \& Alvarez-Sala-Walther, L. A. (2019). The fluid aspect of the Mediterranean diet in the prevention and management of cardiovascular disease and diabetes: the role of polyphenol content in moderate consumption of wine and olive oil. Nutrients, 11(11), 2833.

Dower, J. I., Geleijnse, J. M., Hollman, P. C., Soedamah-Muthu, S. S., \& Kromhout, D. (2016). Dietary epicatechin intake and 25-y risk of cardiovascular mortality: the Zutphen Elderly Study. The American journal of clinical nutrition, 104(1), 58-64.

Einvik, G., Ole Klemsdal, T., Sandvik, L., \& Hjerkinn, E. M. (2010). A randomized clinical trial on $n-3$ polyunsaturated fatty acids supplementation and allcause mortality in elderly men at high cardiovascular risk. European Journal of Cardiovascular Prevention \& Rehabilitation, 17(5), 588-592.

Emerging Risk Factors Collaboration. (2011). Separate and combined associations of body-mass index and abdominal adiposity with cardiovascular disease: collaborative analysis of 58 prospective studies. The Lancet, 377(9771), 1085-1095. 
Estruch, R., Ros, E., Salas-Salvadó, J., Covas, M. I., Corella, D., Arós, F., ... \& Lamuela-Raventos, R. M. (2018). Primary prevention of cardiovascular disease with a Mediterranean diet supplemented with extra-virgin olive oil or nuts. New England journal of medicine, 378(25), e34.

Ferreira, I. C., Barros, L., \& Abreu, R. (2009). Antioxidants in wild mushrooms. Current Medicinal Chemistry, 16(12), 1543-1560.

Food and Drug Administration. (1999). FDA approves new health claim for soy protein and coronary heart disease. FDA Talk Paper.

Giavasis, I. (2014). Bioactive fungal polysaccharides as potential functional ingredients in food and nutraceuticals. Current opinion in biotechnology, 26, 162-173.

Gil-Izquierdo, A., L Penalvo, J., I Gil, J., Medina, S., N Horcajada, M., Lafay, S., ... \& Ferreres, F. (2012). Soy isoflavones and cardiovascular disease epidemiological, clinical and-omics perspectives. Current pharmaceutical biotechnology, 13(5), 624-631.

Granato, D., Barba, F. J., Bursać Kovačević, D., Lorenzo, J. M., Cruz, A. G., \& Putnik, P. (2020) Functional foods: Product development, technological trends, efficacy testing and safety. Annual Review of Food Science and Technology, 11, 93-118.

Grosso, G., Micek, A., Godos, J., Pajak, A., Sciacca, S., Galvano, F., \& Giovannucci, E. L. (2017). Dietary flavonoid and lignan intake and mortality in prospective cohort studies: Systematic review and dose-response meta-analysis. American journal of epidemiology, 185(12), 1304-1316.

Grosso, G., Stepaniak, U., Topor-Mądry, R., Szafraniec, K., \& Pająk, A. (2014). Estimated dietary intake and major food sources of polyphenols in the Polish arm of the HAPIEE study. Nutrition, 30(11-12), 1398-1403.

Hartley, L., Flowers, N., Holmes, J., Clarke, A., Stranges, S., Hooper, L., \& Rees, K. (2013). Green and black tea for the primary prevention of cardiovascular disease. Cochrane Database of Systematic Reviews, (6).

Herrera, D., Molina, A., Buhlin, K., \& Klinge, B. (2020). Periodontal diseases and association with atherosclerotic disease. Periodontology 2000, 83(1), 66-89.

Hodis, H. N., Mack, W. J., Kono, N., Azen, S. P., Shoupe, D., Hwang-Levine, J., ... \& Selzer, R. H. (2011). Isoflavone soy protein supplementation and atherosclerosis progression in healthy postmenopausal women: a randomized controlled trial. Stroke, 42(11), 3168-3175.
Hügel, H. M., Jackson, N., May, B., Zhang, A. L., \& Xue, C. C. (2016). Polyphenol protection and treatment of hypertension. Phytomedicine, 23(2), 220-231.

Ikeda, A., Iso, H., Yamagishi, K., Iwasaki, M., Yamaji, T., Miura, T., ... \& JPHC Study Group. (2018). Plasma tea catechins and risk of cardiovascular disease in middle-aged Japanese subjects: The JPHC study. Atherosclerosis, 277, 90-97.

Ivey, K. L., Hodgson, J. M., Croft, K. D., Lewis, J. R., \& Prince, R. L. (2015). Flavonoid intake and all-cause mortality. The American journal of clinical nutrition, 101(5), 1012-1020.

Jayakumar, T., Sakthivel, M., Thomas, P. A., \& Geraldine, P. (2008). Pleurotus ostreatus, an oyster mushroom, decreases the oxidative stress induced by carbon tetrachloride in rat kidneys, heart and brain. Chemico-Biological Interactions, 176(2-3), 108-120.

Jonsson, A. L., \& Bäckhed, F. (2017). Role of gut microbiota in atherosclerosis. Nature Reviews Cardiology, 14(2), 79-87.

Joyce, S. A., Kamil, A., Fleige, L., \& Gahan, C. G. (2019). The cholesterol-lowering effect of oats and oat beta glucan: modes of action and potential role of bile acids and the microbiome. Frontiers in Nutrition, 6, 171.

Kamiloglu, S., Demirci, M., Selen, S., Toydemir, G., Boyacioglu, D., \& Capanoglu, E. (2014). Home processing of tomatoes (Solanum lycopersicum): effects on in vitro bioaccessibility of total lycopene, phenolics, flavonoids and antioxidant capacity. Journal of the Science of Food and Agriculture, 94(11), 2225-2233.

Katz, D. L., Doughty, K., \& Ali, A. (2011). Cocoa and chocolate in human health and disease. Antioxidants $\&$ redox signaling, 15(10), 2779-2811.

Keenan, N. L., Rosendorf, K. A., \& Centers for Disease Control and Prevention (CDC). (2011). Prevalence of hypertension and controlled hypertensionUnited States, 2005-2008. MMWR Surveill Summ, 60(Suppl), 94-97.

Key, T. J. (2011). Fruit and vegetables and cancer risk. British journal of cancer, 104(1), 6-11.

Khalesi, S., Irwin, C., \& Schubert, M. (2015). Flaxseed consumption may reduce blood pressure: a systematic review and meta-analysis of controlled trials. The Journal of nutrition, 145(4), 758-765.

Kimatu, B. M., Zhao, L., Biao, Y., Ma, G., Yang, W., Pei, F., \& Hu, Q. (2017). Antioxidant potential of edible mushroom (Agaricus bisporus) protein hydrolysates and their ultrafiltration fractions. Food Chemistry, 230, 58-67. 
Kondreddy, V. K. R., Anikisetty, M., \& Naidu, K. A. (2016). Medium-chain triglycerides and monounsaturated fatty acids potentiate the beneficial effects of fish oil on selected cardiovascular risk factors in rats. The Journal of nutritional biochemistry, 28, 91-102.

Lackland, D. T., Roccella, E. J., Deutsch, A. F., Fornage, M., George, M. G., Howard, G., ... \& Schwamm, L. H. (2014). Factors influencing the decline in stroke mortality: a statement from the American Heart Association/American Stroke Association. Stroke, 45(1), 315-353.

Li, C., Yan, Q., Tang, S., Xiao, W., \& Tan, Z. (2018). LTheanine protects $\mathrm{H} 9 \mathrm{c} 2$ cells from hydrogen peroxide-induced apoptosis by enhancing antioxidant capability. Medical science monitor: international medical journal of experimental and clinical research, 24, 2109.

Li, H., \& Förstermann, U. (2012). Red wine and cardiovascular health. Circulation research, 111(8), 959-961.

Liu, J., Jia, L., Kan, J., \& Jin, C. H. (2013). In vitro and in vivo antioxidant activity of ethanolic extract of white button mushroom (Agaricus bisporus). Food and chemical toxicology, 51, 310-316.

Liu, K., Daviglus, M. L., Loria, C. M., Colangelo, L. A., Spring, B., Moller, A. C., \& Lloyd-Jones, D. M. (2012). Healthy lifestyle through young adulthood and the presence of low cardiovascular disease risk profile in middle age: the Coronary Artery Risk Development in (Young) Adults (CARDIA) study. Circulation, 125(8), 996-1004.

Lozano, R., Naghavi, M., Foreman, K., Lim, S., Shibuya, K., Aboyans, V., ... \& AlMazroa, M. A. (2012). Global and regional mortality from 235 causes of death for 20 age groups in 1990 and 2010: a systematic analysis for the Global Burden of Disease Study 2010. The lancet, 380(9859), 2095-2128.

Manna, E., \& Maiti, S. (2016). Cardio-protecting effect of natural bioactive compound (polyphenol) by inhibiting ldl oxidation with the scavenging of reactive oxygen species (ROS). J Clin Exp Cardiolog, 7(453), 2.

Matthews, L. B., Kunkel, M. E., Acton, J. C., Ogale, A. A., \& Dawson, P. L. (2011). Bioavailability of soy protein and corn zein films. Food and Nutrition Sciences, 2011.

Meier, T., Gräfe, K., Senn, F., Sur, P., Stangl, G. I., Dawczynski, C., .. \& Lorkowski, S. (2019). Cardiovascular mortality attributable to dietary risk factors in 51 countries in the WHO European Region from 1990 to 2016: a systematic analysis of the Global Burden of Disease Study. European journal of epidemiology, 34(1), 37-55.
Mensink, R. P., de Jong, A., Lütjohann, D., Haenen, G. R., \& Plat, J. (2010). Plant stanols dose-dependently decrease LDL-cholesterol concentrations, but not cholesterol-standardized fat-soluble antioxidant concentrations, at intakes up to $9 \mathrm{~g} / \mathrm{d}$. The American journal of clinical nutrition, 92(1), 24-33.

Miller, V., Cudhea, F., Singh, G., Micha, R., Shi, P., Zhang, J., ... \& Mozaffarian, D. (2019). Estimated Global, Regional and National Cardiovascular Disease Burdens Related to Fruit and Vegetable Consumption: An Analysis from the Global Dietary Database (FS01-01-19). Current developments in nutrition, 3(Supplement_1), nzz028-FS01.

Mink, P. J., Scrafford, C. G., Barraj, L. M., Harnack, L., Hong, C. P., Nettleton, J. A., \& Jacobs Jr, D. R. (2007). Flavonoid intake and cardiovascular disease mortality: a prospective study in postmenopausal women. The American journal of clinical nutrition, 85(3), 895-909.

Mojani, M. S., Ghasemzadeh, A., Rahmat, A., Loh, S. P., \& Ramasamy, R. (2014). Assessment of bioactive compounds, nutritional composition and antioxidant activity of Malaysian young ginger (Zingiber officinale Roscoe). International Food Research Journal, 21(5), 1931.

Mozaffarian, D., Benjamin, E. J., Go, A. S., Arnett, D. K., Blaha, M. J., Cushman, M., ... \& Howard, V. J. (2016). Executive summary: heart disease and stroke statistics-2016 update: a report from the American Heart Association. Circulation, 133(4), 447-454.

Naghavi, M., Abajobir, A. A., Abbafati, C., Abbas, K. M., Abd-Allah, F., Abera, S. F., ... \& Ahmadi, A. (2017). Global, regional and national age-sex specific mortality for 264 causes of death, 1980-2016: a systematic analysis for the Global Burden of Disease Study 2016. The Lancet, 390(10100), 1151-1210.

Omar, S. H., \& Al-Wabel, N. A. (2010). Organosulfur compounds and possible mechanism of garlic in cancer. Saudi Pharmaceutical Journal, 18(1), 51-58.

Orem, A., Yucesan, F. B., Orem, C., Akcan, B., Kural, B. V., Alasalvar, C., \& Shahidi, F. (2013). Hazelnutenriched diet improves cardiovascular risk biomarkers beyond a lipid-lowering effect in hypercholesterolemic subjects. Journal of clinical lipidology, 7(2), 123-131.

Othman, R. A., Moghadasian, M. H., \& Jones, P. J. (2011). Cholesterol-lowering effects of oat $\beta$-glucan. Nutrition reviews, 69(6), 299-309.

Oyama, J. I., Shiraki, A., Nishikido, T., Maeda, T., Komoda, H., Shimizu, T., ... \& Node, K. (2017). EGCG, a green tea catechin, attenuates the progression of heart failure induced by the heart/muscle-specific deletion of MnSOD in mice. Journal of Cardiology, 69(2), 417-427. 
Peter, S., Chopra, S., \& Jacob, J. J. (2013). A fish a day, keeps the cardiologist away!-A review of the effect of omega-3 fatty acids in the cardiovascular system. Indian journal of endocrinology and metabolism, 17(3), 422.

Petyaev, I. M., Klochkov, V. A., Chalyk, N. E., Pristensky, D. V., Chernyshova, M. P., Kyle, N. H., \& Bashmakov, Y. K. (2018). Markers of hypoxia and oxidative stress in aging volunteers ingesting lycosomal formulation of dark chocolate containing astaxanthin. The journal of nutrition, health \& aging, 22(9), 1092-1098.

Pourmasoumi, M., Hadi, A., Rafie, N., Najafgholizadeh, A., Mohammadi, H., \& Rouhani, M. H. (2018). The effect of ginger supplementation on lipid profile: A systematic review and meta-analysis of clinical trials. Phytomedicine, 43, 28-36.

Raji, P., Seyedalipour, B., \& Moghaddam, A. H. (2019). Effect of garlic extract and $\mathrm{N}$-acetylcysteine against fenvalerate-induced oxidative stress in the serum and testis tissue of rat. Journal of Gorgan University of Medical Sciences, 21(2).

Ras, R. T., Geleijnse, J. M., \& Trautwein, E. A. (2014). LDL-cholesterol-lowering effect of plant sterols and stanols across different dose ranges: a meta-analysis of randomised controlled studies. British Journal of Nutrition, 112(2), 214-219.

Reis, F. S., Martins, A., Vasconcelos, M. H., Morales, P., \& Ferreira, I. C. (2017). Functional foods based on extracts or compounds derived from mushrooms. Trends in Food Science \& Technology, 66, 48-62.

Ried, K., Fakler, P., \& Stocks, N. P. (2017). Effect of cocoa on blood pressure. The Cochrane Library.

Ried, K., Frank, O. R., \& Stocks, N. P. (2013). Aged garlic extract reduces blood pressure in hypertensives: a dose-response trial. European Journal of Clinical Nutrition, 67(1), 64-70.

Rodriguez-Leyva, D., Weighell, W., Edel, A. L., LaVallee, R., Dibrov, E., Pinneker, R., ... \& Pierce, G. N. (2013). Potent antihypertensive action of dietary flaxseed in hypertensive patients. Hypertension, 62(6), 1081-1089.

Ryan, P. M., Ross, R. P., Fitzgerald, G. F., Caplice, N. M., \& Stanton, C. (2015). Functional food addressing heart health: do we have to target the gut microbiota?. Current Opinion in Clinical Nutrition \& Metabolic Care, 18(6), 566-571.

Sacco, R. L., Roth, G. A., Reddy, K. S., Arnett, D. K., Bonita, R., Gaziano, T. A., ... \& Murray, C. J. (2016). The heart of 25 by 25 : achieving the goal of reducing global and regional premature deaths from cardiovascular diseases and stroke: a modeling study from the American Heart Association and World Heart Federation. Circulation, 133(23), e674-e690.
Sandoval-Ramírez, B. A., Catalán, Ú., Calderón-Pérez, L., Companys, J., Pla-Pagà, L., Ludwig, I. A., ... \& Solà, R. (2020). The effects and associations of whole-apple intake on diverse cardiovascular risk factors. A narrative review. Critical Reviews in Food Science and Nutrition, 1-14.

Saptarini, N. M. (2013). Structure-based in silico study of 6-gingerol, 6-ghogaol and 6-paradol, active compounds of ginger (Zingiber officinale) as $\mathrm{COX}$ 2 inhibitors.

Saravanan, P., Davidson, N. C., Schmidt, E. B., \& Calder, P. C. (2010). Cardiovascular effects of marine omega-3 fatty acids. The Lancet, 376(9740), 540-550.

Scolaro, B., de Andrade, L. F., \& Castro, I. A. (2020). Cardiovascular Disease Prevention: The Earlier the Better? A Review of Plant Sterol Metabolism and Implications of Childhood Supplementation. International Journal of Molecular Sciences, 21(1), 128 .

Shoaib, M., Shehzad, A., Butt, M. S., Saeed, M., Raza, H., Niazi, S., \& Shakeel, A. (2016). AN OVERVIEW: GINGER, A TREMENDOUS HERB. Journal of Global Innovations in Agricultural and Social Sciences), 4 (4), 172-187.

Singh, G. M., Danaei, G., Pelizzari, P. M., Lin, J. K., Cowan, M. J., Stevens, G. A., ... \& Lim, S. S. (2012). The age associations of blood pressure, cholesterol and glucose: analysis of health examination surveys from international populations. Circulation, 125(18), 2204-2211.

Smet, E. D., Mensink, R. P., \& Plat, J. (2012). Effects of plant sterols and stanols on intestinal cholesterol metabolism: suggested mechanisms from past to present. Molecular nutrition \& food research, 56(7), 1058-1072.

Smith, C. E., \& Tucker, K. L. (2011). Health benefits of cereal fibre: a review of clinical trials. Nutrition research reviews, 24(1), 118-131.

Sobenin, I. A., Myasoedova, V. A., Iltchuk, M. I., Zhang, D. W., \& Orekhov, A. N. (2019). Therapeutic effects of garlic in cardiovascular atherosclerotic disease. Chinese journal of natural medicines, 17(10), 721-728.

Song, W., Derito, C. M., Liu, M. K., He, X., Dong, M., \& Liu, R. H. (2010). Cellular antioxidant activity of common vegetables. Journal of Agricultural and Food Chemistry, 58(11), 6621-6629.

Stirpe, M., Palermo, V., Bianchi, M. M., Silvestri, R., Falcone, C., Tenore, G., ... \& Mazzoni, C. (2017). Annurca apple (M. pumila Miller cv Annurca) extracts act against stress and ageing in S. cerevisiae yeast cells. BMC complementary and alternative medicine, 17(1), 1-7. 
Tran, G. B., Dam, S. M., \& Le, N. T. T. (2018). Amelioration of single clove black garlic aqueous extract on dyslipidemia and hepatitis in chronic carbon tetrachloride intoxicated Swiss Albino mice. International journal of hepatology, 2018.

Valverde, M. E., Hernández-Pérez, T., \& Paredes-López, O. (2015). Edible mushrooms: improving human health and promoting quality life. International journal of microbiology, 2015.

van der Hooft, J. J., Akermi, M., Ünlü, F. Y., Mihaleva, V., Roldan, V. G., Bino, R. J., ... \& Vervoort, J. (2012). Structural annotation and elucidation of conjugated phenolic compounds in black, green and white tea extracts. Journal of Agricultural and Food Chemistry, 60(36), 8841-8850.

Wang, N., Jiang, S., Zhang, Z., Fang, H., Xu, H., Wang, Y., \& Chen, X. (2018). Malus sieversii: the origin, flavonoid synthesis mechanism and breeding of redskinned and red-fleshed apples. Horticulture Research, 5(1), 1-12.

Wang, Y., Gallegos, J. L., Haskell-Ramsay, C., \& Lodge, J. K. (2020). Effects of chronic consumption of specific fruit (berries, citrus and cherries) on CVD risk factors: a systematic review and metaanalysis of randomised controlled trials. European Journal of Nutrition, 1-25.

Wasser, S. (2014). Medicinal mushroom science: Current perspectives, advances, evidences and challenges. Biomedical journal, 37(6).

Wofford, M. R., Rebholz, C. M., Reynolds, K., Chen, J., Chen, C. S., Myers, L., ... \& He, J. (2012). Effect of soy and milk protein supplementation on serum lipid levels: a randomized controlled trial. European journal of clinical nutrition, 66(4), 419-425.
Wolever, T. M., Tosh, S. M., Gibbs, A. L., Brand-Miller, J., Duncan, A. M., Hart, V., ... \& Wood, P. J. (2010). Physicochemical properties of oat $\beta$-glucan influence its ability to reduce serum LDL cholesterol in humans: a randomized clinical trial. The American journal of clinical nutrition, 92(4), 723-732.

World Health Organization. (2003). Diet, nutrition and the prevention of chronic diseases: report of a joint WHO/FAO expert consultation (Vol. 916). World Health Organization.

Xia, E. Q., Deng, G. F., Guo, Y. J., \& Li, H. B. (2010). Biological activities of polyphenols from grapes. International journal of molecular sciences, 11(2), 622-646.

Yang, C., Li, L., Yang, L., Lü, H., Wang, S., \& Sun, G. (2018). Anti-obesity and Hypolipidemic effects of garlic oil and onion oil in rats fed a high-fat diet. Nutrition \& metabolism, 15(1), 43.

Yang, G. Z., Wang, Z. J., Bai, F., Qin, X. J., Cao, J., Lv, J. Y., \& Zhang, M. S. (2015). Epigallocatechin-3gallate protects HUVECs from PM2. 5-induced oxidative stress injury by activating critical antioxidant pathways. Molecules, 20(4), 6626-6639.

Yuan, J. M. (2013). Cancer prevention by green tea: evidence from epidemiologic studies. The American journal of clinical nutrition, 98(6), 1676S-1681S.

Zhang, X., Shu, X. O., Xiang, Y. B., Yang, G., Li, H., Gao, J., \& Zheng, W. (2011). Cruciferous vegetable consumption is associated with a reduced risk of total and cardiovascular disease mortality. The American journal of clinical nutrition, 94(1), 240-246. 